IP Periodica Polytechnica Civil Engineering

\author{
62(2), pp. 444-450, 2018 \\ https://doi.org/10.3311/PPci.10752 \\ Creative Commons Attribution (i)
}

RESEARCH ARTICLE

\section{Investigations on Vehicle Interaction with CWR Tracks Considering Some Aspects of Rail Support Modulus}

\author{
Seyed-Ali Mosayebi ${ }^{1 *}$, Jabbar-Ali Zakeri ${ }^{2}$, Morteza Esmaeili ${ }^{2}$
}

Received 16 March 2017; Revised 30 October 2017; Accepted 13 November 2017

\begin{abstract}
One of the important parameters for controlling the behavior of continuous welded rail (CWR) in railway tracks is rail support modulus. Reviewing the technical literature reveals some elapsed points in this regard such as continuous or discrete supports, V-shaped rail irregularity and geometrical stiffness which can considerably affect on the vehicle-track dynamic interaction. So, the present study was allocated to numerical investigating the effects of aforementioned parameters on the vehicle-track dynamic interaction. In this matter, the finite element model of ballasted railway track in conjunction with multi-body dynamics model of vehicle was developed and they simultaneously solved numerically. This preliminary model was verified through comparison of the results with published works in this area. Consequently the model was promoted considering continuous and discrete support condition, implementing the $V$-shaped irregularity and geometrical stiffness. In each step, the results of the extended models were completely presented in the form track structure response.
\end{abstract}

\section{Keywords}

railway track, rail support modulus, vehicle-track system, finite element method, continuous or discrete supports, $V$-shaped rail irregularity, geometric stiffness

1 School of Railway Engineering, Iran University of Science and Technology, Tehran, Iran

2 The Center of Excellence in Railway Transportation, School of Railway Engineering, Iran University of Science and Technology, Tehran, Iran

*Corresponding author, email: mosayebi@iust.ac.ir

\section{Introduction}

The mechanical behavior of continuous welded rail (CWR) tracks under moving vehicles is an important issue which should be investigated using suitable computational tools. Till now, several researchers have already worked in the field of analysis of railway tracks. For instance, Zhai and Cai [1] studied the vehicle-track interaction considering a system of lumped masses and discrete supports. Fryba [2] studied the effects of moving loads on the beam as simplified railway track. Dahlberg [3] investigated the dynamic behavior of railway tracks. Breul and Saussine [4] investigated the ballast mechanical specifications by experimental studies. Zakeri and Xia [5] presented a train - track dynamic interaction model for analyzing the ballasted railway tracks. Zakeri et al. [6, 7] studied the effects of rail irregularity in dynamic performance of ballasted tracks. Wang et al. [8] investigated the beam behavior under the moving loads. Zakeri and Ghorbani [9] investigated the dynamic behavior of ballasted and slab tracks. Mosayebi et al. [10] studied the effects of support stiffness on behavior of ballasted railway tracks. Also, Esmaeili et al. [11] studied train induced ground vibrations due to moving loads. Rail support modulus is known as one of the most important parameters which can affect on the dynamic behavior of railway tracks. In this regard, Selig and Waters [12] investigated the railway track specifications such as stiffness of track parts. Cai et al. [13] studied the static track modulus. Kerr $[14,15]$ examined the rail support modulus in the railway tracks. Mosayebi et al. [16] investigated the ballasted track performance due to a passing locomotive by using numerical analyses and field tests. Zakeri et al. [17] studied the effects of track stiffness on the behavior of railway tracks.

Reviewing the above-mentioned literature evidently shows some unconsidered aspects in numerical investigating the vehicle-track interaction focusing on the role of rail support modulus on dynamic interaction of moving vehicle.

In this study some important issues of V-shaped rail irregularity and geometrical rail support stiffness are studied using finite element model of coupled vehicle and railway track. The developed preliminary model of track is validated by comparisons of the results with those presented by Zakeri and Ghorbani 
[9]. In the next stage, the response of track with continuous supports was compared with track including discrete supports and some important points were presented from analytical point of view. In continuation, the effect of rail support modulus in conjunction with various amplitudes of $\mathrm{V}$-shaped rail irregularity on the dynamic behavior of railway track with continuous supports was investigated. In the final stage, the effect of geometric stiffness and rail temperature on the behavior of railway tracks was studied. As practical outcomes of the research, several equations were derived for various engaged parameters.

\section{Railway track model}

Ballasted track superstructure consists of rail, sleeper, ballast, and bed parts. In model of beam on elastic foundation, an equivalent stiffness is considered instead of stiffness of all of the mentioned track components. In numerical analysis of beam on the elastic foundation, the term of foundation stiffness (rail support modulus) should be considered together with the beam stiffness. Fig. 1 indicates the model of railway track located on the continuous supports. This model contains the beam elements on the elastic foundation (Fig. 2).

Railway Track

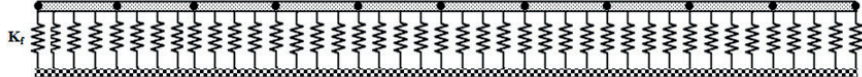

Fig. 1 Railway track model including beam elements

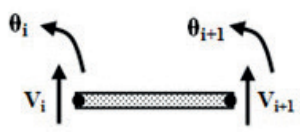

Fig. 2 Beam element

Considering the $K_{f}$ as rail support modulus, the stiffness matrix for each element is calculated as follows [8]:

$$
\left[K_{F}\right]=\int K_{f}[f(x)]^{T}[f(x)] d A
$$

In this equation, $f(x)$ and $K_{f}$ are shape function and elasticity constant of foundation respectively. The shape function is determined as follows:

$$
\begin{aligned}
& f(x)=\frac{1}{L^{3}}\left[2 x^{3}-3 x^{2} L+L^{3} \quad x^{3} L-2 x^{2} L^{2}+x L^{3}\right. \\
& \left.-2 x^{3}+3 x^{2} L \quad x^{3} L-x^{2} L^{2}\right]
\end{aligned}
$$

In this equation, parameters of $\mathrm{x}$ and $\mathrm{L}$ are distance of load from the first node and length of beam element respectively. The stiffness matrix of railway track on the elastic foundation is calculated as follows:

$$
\left[K_{F}\right]=\left[\begin{array}{cccc}
\frac{13 b L K_{f}}{35} & \frac{11 b L^{2} K_{f}}{210} & \frac{9 b L K_{f}}{70} & -\frac{13 b L^{2} K_{f}}{420} \\
\frac{11 b L^{2} K_{f}}{210} & \frac{b L^{3} K_{f}}{105} & \frac{13 b L^{2} K_{f}}{420} & -\frac{b L^{3} K_{f}}{140} \\
\frac{9 b L K_{f}}{70} & \frac{13 b L^{2} K_{f}}{420} & \frac{13 b L K_{f}}{35} & -\frac{11 b L^{2} K_{f}}{210} \\
-\frac{13 b L^{2} K_{f}}{420} & -\frac{b L^{3} K_{f}}{140} & -\frac{11 b L^{2} K_{f}}{210} & \frac{b L^{3} K_{f}}{105}
\end{array}\right]
$$

In this matrix, $K_{f}, b$, and $L$ are elasticity constant of foundation (rail support modulus), the width of beam and length of the element respectively. Consequently, the stiffness matrix of the beam on elastic foundation $\left[K_{b e f}\right]$ is assessed as follows:

$$
\left[K_{\text {bef }}\right]=\left[K_{B}\right]+\left[K_{F}\right]
$$

In this equation, $\left[K_{B}\right]$, and $\left[K_{F}\right]$ are the beam and foundation stiffness matrix respectively. Also, the beam stiffness matrix $\left[K_{B}\right]$ is obtained as follows:

$$
\left[K_{B}\right]=\frac{E I}{L^{3}}\left[\begin{array}{cccc}
12 & 6 L & -12 & 6 L \\
6 L & 4 L^{2} & -6 L & 2 L^{2} \\
-12 & -6 L & 12 & -6 L \\
6 L & 2 L^{2} & -6 L & 4 L^{2}
\end{array}\right]
$$

In this matrix, $E, I$ and $L$ are elasticity modulus, moment of inertia and length of beam element respectively. Also, the mass $\left[M_{R}\right]$ and damping $\left[C_{R}\right]$ matrix are determined as follows:

$$
\begin{gathered}
{\left[M_{R}\right]=\frac{m L}{420}\left[\begin{array}{cccc}
156 & 22 L & 54 & -13 L \\
22 L & 4 L^{2} & 13 L & -3 L^{2} \\
54 & 13 L & 156 & -22 L \\
-13 L & -3 L^{2} & -22 L & 4 L^{2}
\end{array}\right]} \\
{\left[C_{R}\right]=\alpha\left[M_{R}\right]+\beta\left[K_{R}\right]}
\end{gathered}
$$

In these equations, $m, \alpha$, and $\beta$ are mass per unit length of track and Rayleigh damping coefficients respectively. It should be noted that the Rayleigh damping coefficients were determined based on the two first natural frequencies of track structure and the reported values in Table 1 have been obtained for $\alpha$ and $\beta$. These values are agreement with those the presented in the technical literature $[6,7,18]$. The motion equation of track model is obtained as follows:

$$
\left[M_{R}\right]\{\ddot{X}\}+\left[K_{R}\right]\{X\}+\left[C_{R}\right]\{\dot{X}\}=\left\{F_{g}\right\}
$$

In this equation, $\left[M_{R}\right],\left[K_{R}\right]$, and $\left[C_{R}\right]$ are the matrix of mass, stiffness, and damping of railway track respectively. Also, $F_{g}$ is gravity of vehicle loads.

\section{Railway vehicle model}

For modeling the railway vehicle, carbody with two bogies including four wheel loads are considered. In this regard, firstly the equations of motion for all parts of vehicle are extracted and then the vehicle matrix is obtained based on the motion equations. In order to determine the force vector, location of passing train load is calculated and then rail points forces are examined based on shape functions. Fig. 3 shows the railway vehicle model. The vehicle model has 10 degrees of freedom including vertical motion of carbody $\left(Z_{c}\right)$, rotational motion of carbody $\left(\theta_{c}\right)$, vertical motion of bogie $1\left(Z_{t 1}\right)$, rotational motion of bogie $1\left(\theta_{t 1}\right)$, vertical motion of bogie $2\left(Z_{t 2}\right)$, rotational motion of bogie $2\left(\theta_{t 2}\right)$, vertical motion of wheel $1\left(Z_{w 1}\right)$, vertical motion of wheel $2\left(Z_{w 2}\right)$, vertical motion of wheel $3\left(Z_{w 3}\right)$ and vertical motion of wheel $4\left(Z_{w 4}\right)$. 


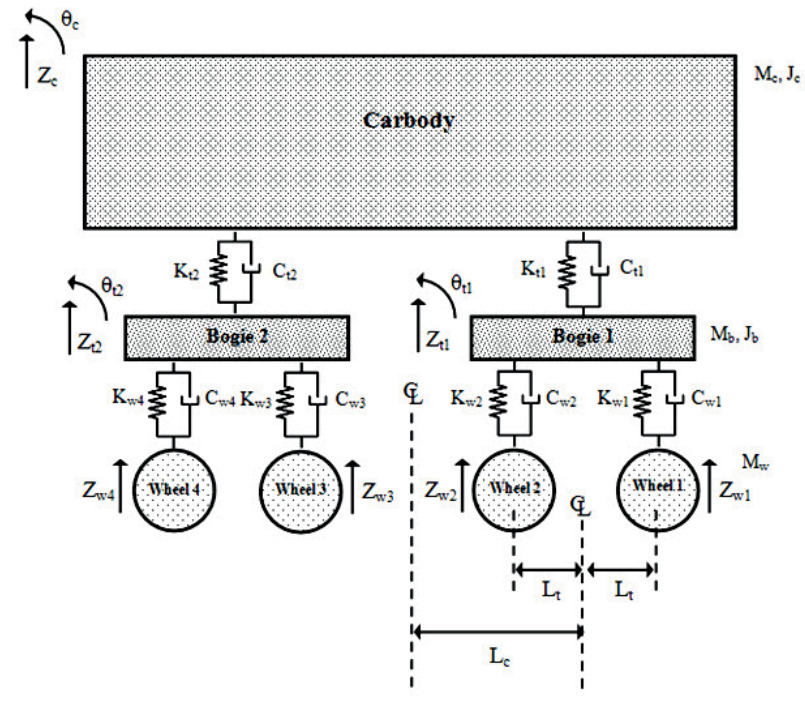

Fig. 3 Railway vehicle model

In Fig. 3, $M_{c}, J_{c}, M_{t}, J_{t}$ and $M_{w}$ are carbody mass, carbody rotational inertia, bogie mass, bogie rotational inertia and wheel mass respectively. Also, $K_{t}, C_{t}, K_{w}$ and $C_{w}$ are bogie stiffness, bogie damping, wheel stiffness and wheel damping respectively. Moreover, $L_{c}$ is the distance of centerlines of carbody and bogie and $L_{t}$ is the distance of centerlines of bogie and wheel. The motion equations of vehicle parts are presented as follows:

Vertical motion equation of carbody $\left(Z_{c}\right)$ :

$$
\begin{aligned}
& M_{c} \ddot{Z}_{c}+K_{t 1}\left(Z_{c}-Z_{t 1}\right)+K_{t 2}\left(Z_{c}-Z_{t 2}\right) \\
& +C_{t 1}\left(\dot{Z}_{c}-\dot{Z}_{t 1}\right)+C_{t 2}\left(\dot{Z}_{c}-\dot{Z}_{t 2}\right)=0
\end{aligned}
$$

Rotational motion equation of carbody $\left(\theta_{c}\right)$ :

$$
\begin{aligned}
& J_{c} \ddot{\theta}_{c}+K_{t 1} L_{c}\left(\theta_{c} L_{c}-Z_{t 1}\right)+K_{t 2} L_{c}\left(\theta_{c} L_{c}+Z_{t 2}\right) \\
& +C_{t 1} L_{c}\left(\dot{\theta}_{c} L_{c}-\dot{Z}_{t 1}\right)+C_{t 2} L_{c}\left(\dot{\theta}_{c} L_{c}+\dot{Z}_{t 2}\right)=0
\end{aligned}
$$

Vertical motion equation of bogie $1\left(Z_{t 1}\right)$ :

$$
\begin{aligned}
& M_{t 1} \ddot{Z}_{t 1}+K_{t 1}\left(Z_{t 1}-Z_{c}-\theta_{c} L_{c}\right)+K_{w 1}\left(Z_{t 1}-Z_{w 1}\right) \\
& +K_{w 2}\left(Z_{t 1}-Z_{w 2}\right)+C_{t 1}\left(\dot{Z}_{t 1}-\dot{Z}_{c}-\dot{\theta}_{c} L_{c}\right) \\
& +C_{w 1}\left(\dot{Z}_{t 1}-\dot{Z}_{w 1}\right)+C_{w 2}\left(\dot{Z}_{t 1}-\dot{Z}_{w 2}\right)=0
\end{aligned}
$$

Rotational motion equation of bogie $1\left(\theta_{t 1}\right)$ :

$$
\begin{aligned}
& J_{t 1} \ddot{\theta}_{t 1}+K_{w 1} L_{t}\left(\theta_{t 1} L_{t}-Z_{w 1}\right)+K_{w 2} L_{t}\left(\theta_{t 1} L_{t}+Z_{w 2}\right) \\
& +C_{w 1} L_{t}\left(\dot{\theta}_{t 1} L_{t}-\dot{Z}_{w 1}\right)+C_{w 2} L_{t}\left(\dot{\theta}_{t 2} L_{t}+\dot{Z}_{w 2}\right)=0
\end{aligned}
$$

Vertical motion equation of bogie $2\left(Z_{t 2}\right)$ :

$$
\begin{aligned}
& M_{t 2} \ddot{Z}_{t 2}+K_{t 2}\left(Z_{t 2}-Z_{c}+\theta_{c} L_{c}\right)+K_{w 3}\left(Z_{t 2}-Z_{w 3}\right) \\
& +K_{w 4}\left(Z_{t 2}-Z_{w 4}\right)+C_{t 2}\left(\dot{Z}_{t 2}-\dot{Z}_{c}+\dot{\theta}_{c} L_{c}\right) \\
& +C_{w 3}\left(\dot{Z}_{t 2}-\dot{Z}_{w 3}\right)+C_{w 4}\left(\dot{Z}_{t 2}-\dot{Z}_{w 4}\right)=0
\end{aligned}
$$

Rotational motion equation of bogie $2\left(\theta_{t 2}\right)$ :

$$
\begin{aligned}
& J_{t 2} \ddot{\theta}_{t 2}+K_{w 3} L_{t}\left(\theta_{t 2} L_{t}-Z_{w 3}\right)+K_{w 4} L_{t}\left(\theta_{t 2} L_{t}+Z_{w 4}\right) \\
& +C_{w 3} L_{t}\left(\dot{\theta}_{t 2} L_{t}-\dot{Z}_{w 3}\right)+C_{w 4} L_{t}\left(\dot{\theta}_{t 2} L_{t}+\dot{Z}_{w 4}\right)=0
\end{aligned}
$$

Vertical motion equation of wheel $1\left(Z_{w 1}\right)$ :

$$
\begin{aligned}
& M_{w 1} \ddot{Z}_{w 1}+K_{w 1}\left(Z_{w 1}-Z_{t 1}-\theta_{t 1} L_{t}\right) \\
& +C_{w 1}\left(\dot{Z}_{w 1}-\dot{Z}_{t 1}-\dot{\theta}_{t 1} L_{t}\right)+F_{w 1}=0
\end{aligned}
$$

Vertical motion equation of wheel $2\left(Z_{w 2}\right)$ :

$$
\begin{aligned}
& M_{w 2} \ddot{Z}_{w 2}+K_{w 2}\left(Z_{w 2}-Z_{t 1}+\theta_{t 1} L_{t}\right) \\
& +C_{w 2}\left(\dot{Z}_{w 2}-\dot{Z}_{t 1}+\dot{\theta}_{t 1} L_{t}\right)+F_{w 2}=0
\end{aligned}
$$

Vertical motion equation of wheel $3\left(Z_{w 3}\right)$ :

$$
\begin{aligned}
& M_{w 3} \ddot{Z}_{w 3}+K_{w 3}\left(Z_{w 3}-Z_{t 2}-\theta_{t 2} L_{t}\right) \\
& +C_{w 3}\left(\dot{Z}_{w 3}-\dot{Z}_{t 2}-\dot{\theta}_{t 2} L_{t}\right)+F_{w 3}=0
\end{aligned}
$$

Vertical motion equation of wheel $4\left(Z_{w 4}\right)$ :

$$
\begin{aligned}
& M_{w 4} \ddot{Z}_{w 4}+K_{w 4}\left(Z_{w 4}-Z_{t 2}+\theta_{t 2} L_{t}\right) \\
& +C_{w 4}\left(\dot{Z}_{w 4}-\dot{Z}_{t 2}+\dot{\theta}_{t 2} L_{t}\right)+F_{w 4}=0
\end{aligned}
$$

Also in these equations, $\mathrm{F}_{w i}$ is the rail-wheel force which is calculated as follows:

$$
F_{w i}=\frac{3}{2} C_{H}\left[Z_{w i}-Z_{r}(x, t)-R(x)\right]^{\frac{3}{2}} \quad i=1,2,3,4
$$

In this equation, $Z_{w}, Z_{r}, C_{H}$ and $R(x)$ are wheel displacement, rail displacement, Hertezian stiffness constant and irregularity shape respectively. Based on the mentioned motion equations of vehicle parts, the mass, stiffness and damping matrix of vehicle model are derived. Then, whole mass, stiffness and damping matrix of vehicle - track dynamic system are calculated by assembling the vehicle and track matrices. Finally, the whole motion equation of system as presented in Eq. 20 is solved with Newmark method according to following algorithm (Fig. 4) $[1,5,6,7]$.

$$
\left[M_{T}\right]\{\ddot{X}\}+\left[K_{T}\right]\{X\}+\left[C_{T}\right]\{\dot{X}\}=\left\{F_{g}+F_{w i}\right\}
$$

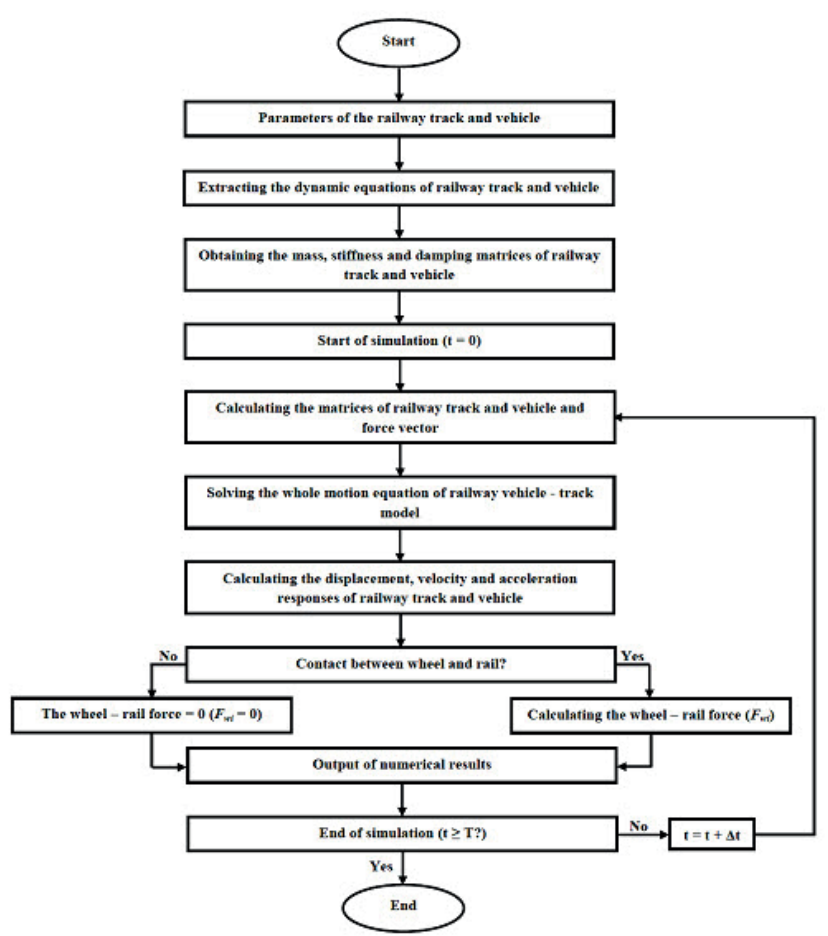

Fig. 4 Solution algorithm for vehicle - track dynamic interaction equations 
In this equation, $\left[M_{T}\right],\left[K_{T}\right]$, and $\left[C_{T}\right]$ are mass, stiffness, and damping of whole system respectively. Also, $F_{g}$ and $F_{w i}$ are gravity of moving vehicle and rail-wheel dynamic force respectively. Regarding to the technical literature [5-7] usually for omitting the beam boundary effects, track length should be considered 1.5 times of train length as $L_{T} \geq 1.5 L_{V}$. Where, $L_{T}$ and $L_{V}$ are the track and vehicle length respectively. Table 1 indicates the important parameters of railway vehicle and track which are used in the present analyses.

\section{Numerical model verification}

In this section for verification the vehicle-track dynamic interaction model, the railway track models with continuous and discrete supports (including rail and sleeper) under the moving train are simulated and their results are compared with the results of Zakeri and Ghorbani study [9]. Fig. 5 depicts the results of the mentioned railway track models.

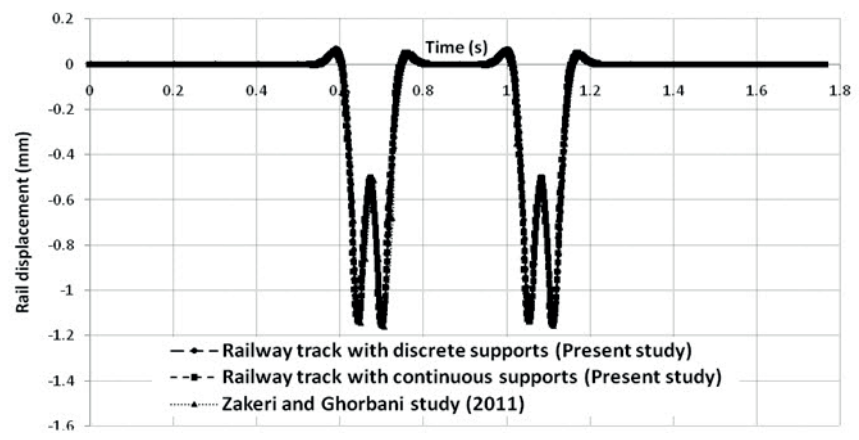

Fig. 5 The results of railway track models with discrete and continuous supports in the present study

As can be observed from Fig. 5, a very good agreement exists between the results of railway track models in the present study and Zakeri and Ghorbani study [9] which confirm the accuracy and validity of the developed numerical models in the present study. Moreover, it should be stated that the maximum difference between discrete and continuous track models is less than 1 percent. In continuation, the effects of rail support modulus are studied on the behavior of railway track.

\section{Effects of rail support modulus by considering the V-shaped rail irregularity}

When continues welded railway tracks, the rails are welded together. During the track operation, by passing the train wheels over the rail connections a type of damage form of the $\mathrm{V}$-shaped rail irregularity is created [19-21]. In this part of paper, the effects of different rail support modulus on the ratio of track displacement to train axle load for various amplitudes of V-shaped rail irregularity are investigated. The V-shaped rail irregularity is presented in Fig. 6.

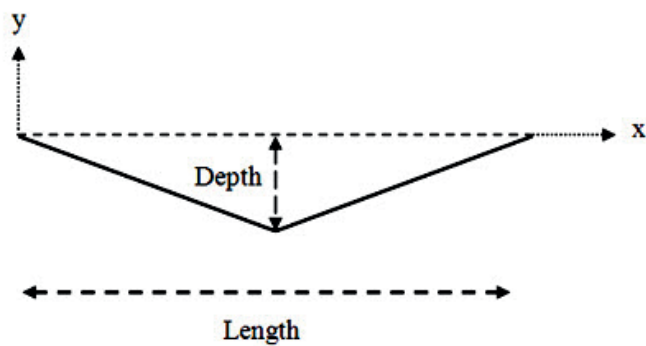

Fig. 6 V-shaped rail irregularity

In this regard, a series of dynamic track analyses are performed and results are presented as ratios of vertical track displacement to axle vehicle load [15]. The following figures show the ratios of the maximum track displacement to vehicle axle load versus the rail support modulus for light and heavy axle train loads corresponding to various irregularity depths.

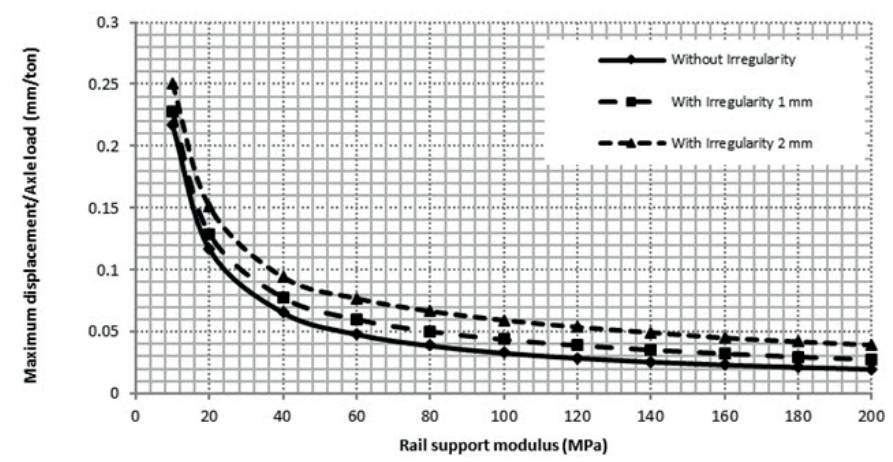

A) Heavy vehicle axle load 20 tons

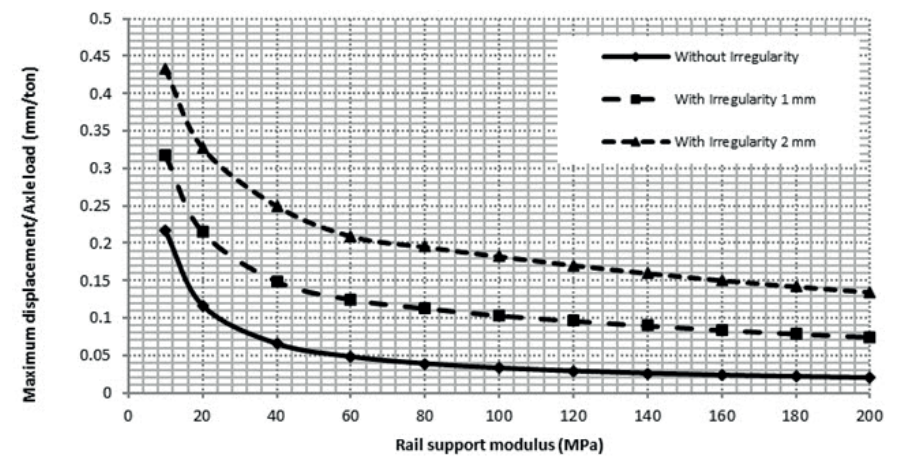

B) Light vehicle axle load 4 tons

Fig. 7 Ratio of track displacement to vehicle load versus rail support modulus for light and heavy axle vehicle loads

As can be observed from Fig. 7, the ratio of track displacement to vehicle axle load decreases by increasing the rail support modulus. This ratio for the heavy and light vehicles in terms of rail support modulus is same when there are not $\mathrm{V}$-shaped rail irregularities in the railway tracks. But, this ratio for the heavy and light vehicles is different when there are $\mathrm{V}$-shaped rail irregularities in the railway track and it increases by increasing the amplitudes of $\mathrm{V}$-shaped rail irregularity. The changes of this ratio for the heavy vehicle loads are less than light vehicle loads. Table 2 depicts the derived equations of this ratio for different $\mathrm{V}$-shaped rail irregularity amplitudes due to the moving light and heavy axle loads. 
Table 1 Railway vehicle and track parameters $[5,6,9,10]$

\begin{tabular}{|c|c|c|c|c|}
\hline Railway vehicle/ track Parts & Parameter & Symbol & values & Unit \\
\hline \multirow{12}{*}{ Vehicle } & Carbody mass & $M_{c}$ & 49500 & $\mathrm{~kg}$ \\
\hline & Carbody rotational inertia & $J_{c}$ & 1700 & t.m $\mathrm{m}^{2}$ \\
\hline & Bogie mass & $M_{t}$ & 10750 & $\mathrm{~kg}$ \\
\hline & Bogie rotational inertia & $J_{t}$ & 9.6 & t.m $\mathrm{m}^{2}$ \\
\hline & Wheel mass & $M_{w}$ & 2200 & $\mathrm{~kg}$ \\
\hline & Bogie stiffness & $K_{t}$ & 1.72 & $\mathrm{MN} / \mathrm{m}$ \\
\hline & Bogie damping & $C_{t}$ & 300 & $\mathrm{kNs} / \mathrm{m}$ \\
\hline & Wheel stiffness & $K_{w}$ & 4.36 & $\mathrm{MN} / \mathrm{m}$ \\
\hline & Wheel damping & $C_{w}$ & 220 & $\mathrm{kNs} / \mathrm{m}$ \\
\hline & Distance of the centerlines of carbody and bogie & $L_{c}$ & 9.5 & $\mathrm{~m}$ \\
\hline & Distance of the centerlines of bogie and wheel & $L_{t}$ & 1.25 & $\mathrm{~m}$ \\
\hline & Vehicle speed & $v$ & 160 & $\mathrm{Km} / \mathrm{hr}$ \\
\hline \multirow{15}{*}{ Track } & Hertezian stiffness constant & $C_{H}$ & $1 \mathrm{e} 11$ & $\mathrm{~N} / \mathrm{m}^{3 / 2}$ \\
\hline & Mass per unit length & $m$ & 60.34 & $\mathrm{~kg} / \mathrm{m}$ \\
\hline & Rayleigh damping coefficient & $\alpha$ & 400 & - \\
\hline & Rayleigh damping coefficient & $\beta$ & $4 e-7$ & - \\
\hline & Track length & $L_{T}$ & 39 & $\mathrm{~m}$ \\
\hline & Distance between sleepers & $L_{r}$ & 60 & $\mathrm{~cm}$ \\
\hline & Rail cross section area & $A$ & $76.9 \mathrm{e}-4$ & $\mathrm{~m}^{2}$ \\
\hline & Rail density & $\rho$ & 7850 & $\mathrm{~kg} / \mathrm{m}^{3}$ \\
\hline & Rail moment of inertia & $I$ & $3055 \mathrm{e}-8$ & $\mathrm{~m}^{4}$ \\
\hline & Rail elasticity modulus & E & $210 \mathrm{e} 9$ & $\mathrm{~N} / \mathrm{m}^{2}$ \\
\hline & Rail pad stiffness & $K_{p}$ & 200 & $\mathrm{MN} / \mathrm{m}$ \\
\hline & Rail bed stiffness & $K_{b}$ & 46 & $\mathrm{MN} / \mathrm{m}$ \\
\hline & length of the rail element & $L$ & 60 & $\mathrm{~cm}$ \\
\hline & Rail support modulus & $K_{f}$ & $10-200$ & $\mathrm{MPa}$ \\
\hline & Thermal expansion coefficient & $\alpha_{0}$ & $1.05 \mathrm{e}-5$ & ${ }^{\circ} \mathrm{C}^{-1}$ \\
\hline
\end{tabular}

Table 2 Derived equations of ratio of track displacement to vehicle axle load respect to rail support modulus

\begin{tabular}{lcc}
\hline $\begin{array}{l}\text { Vehicle Axle } \\
\text { loads (ton) }\end{array}$ & $\begin{array}{c}\text { Amplitude of V-shaped } \\
\text { rail irregularity (mm) }\end{array}$ & $\begin{array}{c}\text { Ratio of track displacement to } \\
\text { vehicle axle load (mm/ton) }\end{array}$ \\
\hline $\begin{array}{l}\text { Heavy vehicle } \\
\text { axle load 20 }\end{array}$ & 0 & $R D=1.258 \mathrm{M}^{-0.78}$ \\
tons & 1 & $R D=1.039 \mathrm{M}^{-0.68}$ \\
Light vehicle & 2 & $R D=0.928 \mathrm{M}^{-0.59}$ \\
axle load 4 & 0 & $R D=1.257 \mathrm{M}^{-0.78}$ \\
tons & 1 & $R D=0.885 \mathrm{M}^{-0.46}$ \\
\hline
\end{tabular}

* In this table, parameter " $\mathrm{M}$ " is rail support modulus (MPa).

According to Table 2, derived equations are presented as power forms $\left(R D=a \cdot M^{b}\right)$. The absolute values of " $b$ " in this equation decrease by increasing the $\mathrm{V}$-shaped rail irregularity amplitudes. In continuation, the effects of geometric stiffness on the beam located on the elastic foundation are investigated.

\section{Effects of rail support modulus by considering geometric stiffness}

For considering the effects of rail support modulus by considering geometric stiffness, the elastic strain energy due to axial load in rail should be considered as follows:

$$
U=\frac{1}{2} \int_{0}^{L} N \times f^{\prime}(x) \times f^{\prime}(x) d x
$$

Then the geometric stiffness matrix is calculated as follows:

$$
\left[K_{G}\right]=\frac{N}{30 L}\left[\begin{array}{cccc}
36 & 3 L & -36 & 3 L \\
3 L & 4 L^{2} & -3 L & -L^{2} \\
-36 & -3 L & 36 & -3 L \\
3 L & -L^{2} & -3 L & 4 L^{2}
\end{array}\right]
$$

In this equation, $K_{G}, L, N$, and $f(x)$ are the geometric stiffness, length of the beam element, axial force, and shape function respectively. The equation of thermal axial force is calculated as follows:

$$
N=E A \alpha_{0} \Delta t
$$

In this equation, $E, A, \alpha_{0}$ and $\Delta t$ are elasticity modulus, beam cross section area, thermal expansion coefficient and the temperature difference respectively. Therefore, the stiffness matrix of beam on the elastic foundation is estimated as follows:

$$
\left[K_{b e f}\right]=\left[K_{B}\right]+\left[K_{F}\right]+\left[K_{G}\right]
$$

In this equation, $\left[K_{B}\right]$ and $\left[K_{F}\right]$ and $\left[K_{G}\right]$ are beam, foundation and geometric stiffness matrices respectively. The following figures indicate the effects of geometric stiffness on the behavior of railway track located on the elastic foundation under the moving vehicle by considering Table 1 . 


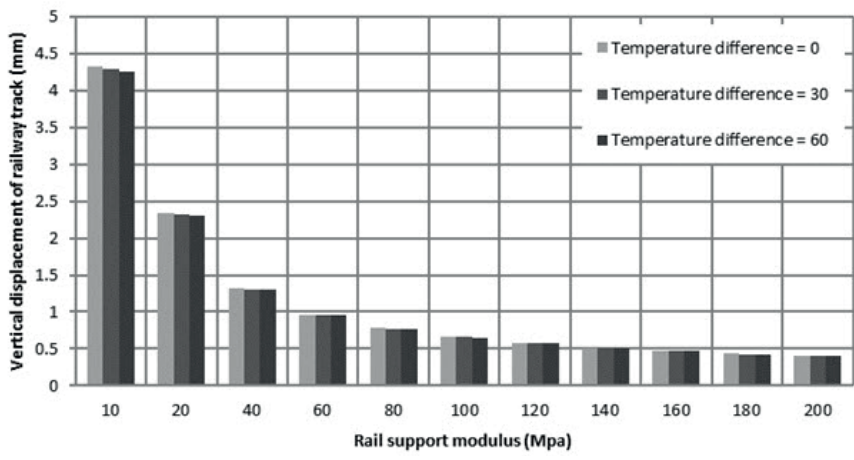

A) Effects of tensile axial loads with various temperature differences

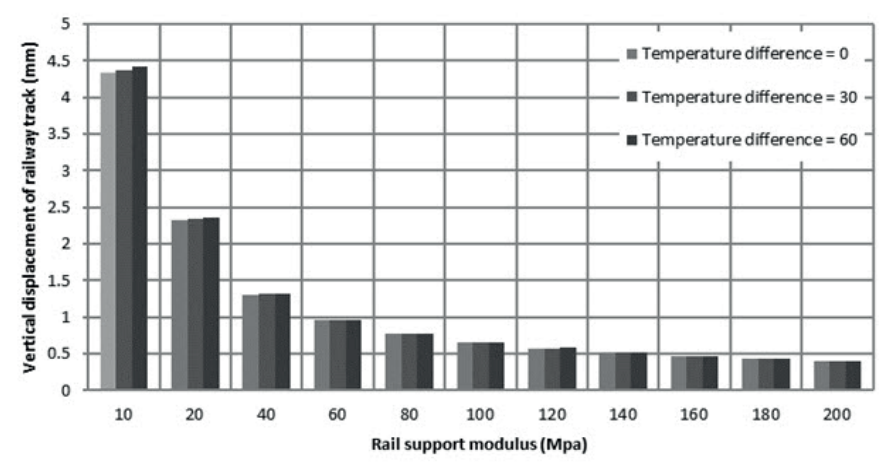

B) Effects of compressive axial loads with various temperature differences

Fig. 8 Railway track displacements by considering geometric stiffness

As can be observed from Fig. 8, the vertical track displacements decrease by increasing the tensile axial forces whereas they increase by increasing the compressive axial forces. Also by increasing the rail support modulus, the effects of tensile and compressive axial forces on the behavior of railway track are negligible. Tables 3 and 4 present the derived equations of track behavior as power forms for tensile and compressive axial loads.

Table 3 Derived equations by considering geometric stiffness for tensile axial load

\begin{tabular}{lcc}
\hline $\begin{array}{l}\text { Temperature difference } \\
\left({ }^{\circ} \mathrm{C}\right)\end{array}$ & Axial force $(\mathrm{kN})$ & $\begin{array}{c}\text { Railway track displacement } \\
(\mathrm{mm})\end{array}$ \\
\hline 0 & 0 & $D=4.239 M^{-1.01}$ \\
30 & 509 & $D=4.205 M^{-1.01}$ \\
60 & 1020 & $D=4.171 M^{-1.01}$ \\
\hline
\end{tabular}

* In this table, parameters “ $M$ ' is rail support modulus (MPa).

Table 4 Derived equations by considering geometric stiffness for compressive axial load

\begin{tabular}{lcc}
\hline $\begin{array}{l}\text { Temperature difference } \\
\left({ }^{\circ} \mathrm{C}\right)\end{array}$ & Axial force $(\mathrm{kN})$ & $\begin{array}{c}\text { Railway track displacement } \\
(\mathrm{mm})\end{array}$ \\
\hline 0 & 0 & $D=4.239 M^{-1.01}$ \\
30 & -509 & $D=4.275 M^{-1.01}$ \\
60 & -1020 & $D=4.313 M^{-1.02}$ \\
\hline
\end{tabular}

* In this table, parameters " $M$ " is rail support modulus (MPa).

Based on the Tables 3 and 4, the coefficients of derived equations decrease by increasing the tensile axial forces whereas they increase by increasing the compressive axial forces.

\section{Conclusions}

The available literature shows that the effects of rail support modulus including some side effects of continuous or discrete supports, V-shaped rail irregularity and geometrical stiffness on the CWR railway track dynamic behavior have not been investigated adequately. In this paper, firstly the modeling procedure of railway track by considering the rail support modulus under the vehicle carbody with two bogies including four axle loads was presented by using the finite element method and then it was verified with the numerical results of previous researches. Then, the response of railway track including continuous supports was compared with track including discrete supports under the moving vehicle. In continuation, the effects of $\mathrm{V}$-shaped rail irregularity and geometric stiffness and rail temperature on the behavior of track were studied. The important results of this study are presented as follows:

The ratio of track displacement to vehicle axle load decreased by increasing the rail support modulus. Also, this ratio increased by increasing the amplitudes of $\mathrm{V}$-shaped rail irregularity.

The ratio of track displacement to axle load for heavy and light vehicles based on rail support modulus was same when there were not $\mathrm{V}$-shaped rail irregularities. But, this ratio for the heavy and light vehicles was different when there were $\mathrm{V}$-shaped rail irregularities. The changes of this ratio under the heavy vehicle loads were less than light vehicle loads.

Derived equations of this ratio $(R D)$ in terms of rail support modulus $(M)$ were presented as power forms $\left(R D=a \cdot M^{\mathrm{b}}\right)$. For heavy vehicle load 20 tons, the coefficients " $a$ " were 1.258, 1.039 and 0.928 and also the coefficients " $b$ " were $-0.78,-0.68$ and -0.59 for amplitudes of $\mathrm{V}$-shaped rail irregularity 0,1 and $2 \mathrm{~mm}$ respectively.

For light vehicle load 4 tons, the coefficients " $a$ " were 1.257 , 0.885 and 1.022 and also the coefficients " $b$ " were $-0.78,-0.46$ and -0.37 for amplitudes of $\mathrm{V}$-shaped rail irregularity 0,1 and $2 \mathrm{~mm}$ respectively.

By considering the geometric stiffness, the vertical track displacements decreased by increasing the tensile axial forces whereas they increased by increasing the compressive axial forces. Also by increasing the rail support modulus, the effects of tensile and compressive axial loads on the behavior of railway track were negligible.

Derived equations of rail vertical displacement $(D)$ respect to rail support modulus $(M)$ were presented as power forms $(D$ $\left.=a \cdot M^{b}\right)$ by considering the geometric stiffness. The coefficients of " $a$ " were 4.239, 4.205 and 4.17 and also the coefficients of " $b$ " were -1.01 for tensile axial loads with the temperature differences 0,30 and $60{ }^{\circ} \mathrm{C}$ respectively. Also for compressive axial loads, the coefficients of " $a$ " were $4.239,4.275$ and 4.313 for temperature differences 0,30 and $60{ }^{\circ} \mathrm{C}$ respectively. 


\section{References}

[1] Zhai, W. M., Cai, Z. "Dynamic interaction between a lumped mass vehicle and a discretely supported continuous rail track". Computers and Structures, 63(5), pp. 987-997. 1997. https://doi.org/10.1016/S00457949(96)00401-4

[2] Fryba, L. "Vibrations of solids and structures under moving loads". English co-edition published by Thomas Telford, 1999. https://doi. org/10.1007/978-94-011-9685-7

[3] Dahlberg, T. "Railway track dynamics - a survey". Linköping University, Sweden, 2003.

[4] Breul, P., Saussine, G. "On site mechanical characterization of the ballast state". Periodica Polytechnica Civil Engineering, 55(1), pp. 31-38. 2011. https://doi.org/10.3311/pp.ci.2011-1.04

[5] Zakeri, J. A., Xia, H. "Sensitivity analysis of track parameters on train - track dynamic interaction". Journal of Mechanical Science and Technology, 22(7), pp. 1299-1304. 2008. https://doi.org/10.1007/s12206008-0316-X

[6] Zakeri, J. A., Xia, H., Fan, J. J. "Dynamic responses of train - track system to single rail irregularity". Latin American Journal of Solids and Structures, 6(2), pp. 89-104. 2009.

[7] Zakeri, J. A. "Determination of "V" Shaped permissible rail defect based on WLR ratio". Iranian Journal of Science \& Technology, Transaction B, Engineering, 33(B1), pp. 129-132. 2009. http://ijstc.shirazu. ac.ir/article_706_d2c4b007e7b0fe42bc5bd55e37c2c085.pdf

[8] Wang, Y., Wang, Y., Zhang, B., Shepard, S. "Transient responses of beam with elastic foundation supports under moving wave load excitation". International Journal of Engineering and Technology, 1(2), pp. 137-143. 2011.

[9] Zakeri, J. A., Ghorbani, V. "Investigation on dynamic behavior of railway track in transition zone". Journal of Mechanical Science and Technology, 25(2), pp. 287-292. 2011. https://doi.org/10.1007/s12206-0101202-x

[10] Mosayebi, S. A., Zakeri, J. A., Esmaeili, M. "Some aspects of support stiffness effects on dynamic ballasted railway tracks". Periodica Polytechnica Civil Engineering, (60)3, pp. 427-436. 2016. https://doi. org/10.3311/PPci.7933
[11] Esmaeili, M., Zakeri, J. A., Mosayebi, S. A. "Effect of sand-fouled ballast on train-induced vibration". International Journal pavement engineering, 15(7), pp. 635-644. 2014. https://doi.org/10.1080/10298436.201 3.818146

[12] Selig, E. T., Waters, J. M. "Track geotechnology and substructure management". Thomas Telford, London, 1994.

[13] Cai, Z., Raymond, G. P., Bathurst, R. J. "Estimate of static track modulus using elastic foundation models". Transportation Research Record, 1470, pp. 65-72. 1994.

[14] Kerr, A. D. "On the determination of the rail support modulus k". International Journal of Solids and Structures, 37(32), pp. 4335-4351. 2000. https://doi.org/10.1016/S0020-7683(99)00151-1

[15] Kerr, A. D. Fundamentals of railway track engineering. Simmons-Boardman Books, 2003.

[16] Mosayebi, S. A., Zakeri, J. A., Esmaeili, M. "Field test investigation and numerical analysis of ballasted track under moving locomotive". Journal of Mechanical Science \& Technology, 30(3), pp. 1065-1069.2016. https://doi.org/10.1007/s12206-016-0209-3

[17] Zakeri, J. A., Esmaeili, M., Mosayebi, S. A., Abbasi, R. "Effects of vibration in desert area caused by moving trains". Journal of Modern Transportation, 20(1), pp. 16-23.2012. https://doi.org/10.1007/ BF03325772

[18] Chopra, A. K. "Dynamics of structures: theory and applications to earthquake engineering". Prentice-Hall, 2001.

[19] Sun, Y. Q., Dhanasekar, M. "A dynamic model for the vertical interaction of the rail track and wagon system". International Journal of Solids and Structures, 39(5), pp. 1337-1359. 2002. https://doi.org/10.1016/ S0020-7683(01)00224-4

[20] Xu, J., Wang, P., Gao, Y., Chen, J., Chen, R. "Geometry evolution of rail weld irregularity and the effect on wheel-rail dynamic interaction in heavy haul railways". Engineering Failure Analysis, 81, pp. 31-44.2017. https://doi.org/10.1016/j.engfailanal.2017.07.009

[21] Mandal, N. K., Dhanasekar, M., Sun, Y. Q. "Impact forces at dipped rail joints". Proceedings of the Institution of Mechanical Engineers, Part F: Journal of Rail and Rapid Transit, 230(1), pp. 271-282.2016. https://doi. org/10.1177/0954409714537816 